\title{
SIT Academy: Online learning using the MOOC approach
}

\author{
Theeranuch Sirikojakorn, Jirayu Chamamahattana, Vajirasak Vanijja, Nipon Charoenkitkarn, and Jonathan \\ H. Chan \\ School of Information Technology, King Mongkut's University of Technology Thonburi (KMUTT), Thailand \\ vajirasak@sit.kmutt.ac.th, nipon@sit.kmutt.ac.th, jonathan@sit.kmutt.ac.th
}

\begin{abstract}
At present, there are several online or elearning opportunities in Thailand that serve Thai students. However, e-learning alone is not sufficient for providing an effective learning environment. The students lack proper continual learning guidance. Similarly, there is usually a gap in communication between students and instructors. Moreover, e-learning alone does not provide a tool to help instructors measure the effectiveness of teaching or manage the course content. In this discussion paper, we present the SIT Academy learning system that is based on a MOOC framework to enhance the learning experience of students and provide a set of useful tools for instructors to manage MOOC course efficiently. Test trials will be undertaken in the fall semester of 2017.
\end{abstract}

Keywords: SIT Academy, MOOC, online learning, elearning, course management

\section{INTRODUCTION}

Evolution of information and communication technology (ICT) has enabled online learning that is complementary to traditional classroom learning. Online learning leverages the internet to deliver a learning experience, often with the aid of a learning management system (LMS). E-learning on the other hand refers to teaching or training through an online medium. Currently, there are several online platforms in Thailand, capable of delivering e-learning, such as the Oliv Classroom on Demand (CoD) platform [1] used in KMUTT. There is increasing interest in providing online learning as researches have shown that ICT-mediated instructions can provide significant improvement in study results [2]. However, e-learning alone is not sufficient for providing an effective learning environment. The students lack continual learning with appropriate feedback. Similarly, there is usually a gap in, as well as a lack of, communication between students and instructors. Moreover, e-learning alone does not provide a tool to help instructors measure the effectiveness of teaching or manage the course content.
Massive Open Online Course (MOOC) is considered a disruptive technology that is reshaping the education sector. MOOC is fast becoming the standard model of online course for higher education globally. Currently, there are several available platforms to develop online classes, for example, open edX, the open source provided by MIT \& Harvard University, and Microsoft Virtual Academy (MVA) by Microsoft.

This research aims to improve upon the current Classroom on Demand (CoD) platform at SIT by developing the SIT Academy web application. The integrated system is based on the open source edX MOOC to address some of the limitations of the current system to enhance the learning experience of Thai students. It would also provide a convenient and beneficial set of tools for instructors to readily manage their MOOC courses.

\section{OBJECTIVES AND SCOPE}

This work aims to develop the SIT Academy web application by emphasizing certain objectives in order to enhance the learning experience of students and provide a set of useful tools for instructors to manage MOOC courses efficiently. Figure 1 provides an overview of the system architecture. SIT Academy is developed using open edX; Web RTC is a free, open project that provides browsers and mobile applications with real-time communications (RTC) capabilities via simple APIs; and Transifex is a web-based translation platform.

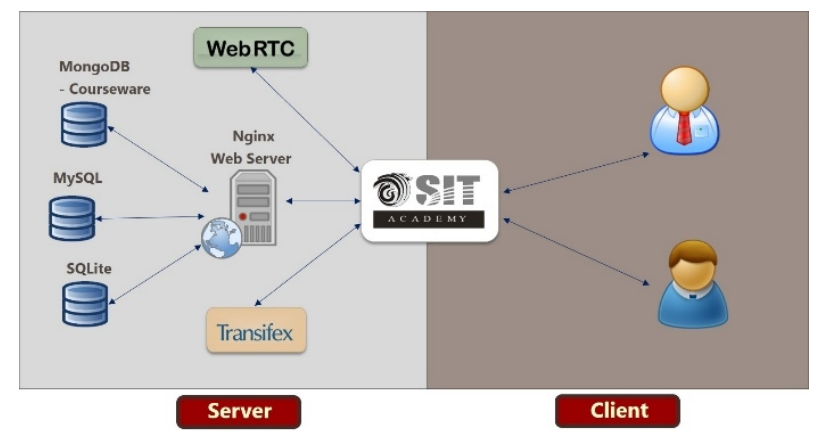

Fig. 1. Architecture of the SIT Academy web application 


\subsection{Objectives}

- To support the instructors in using the system for upload video contents;

- To assist students make decision to enroll in courses that are appropriate for them;

- To provide a tool to help students manage their courses easily;

- To provide a tool that encourages student learning by enabling practicing online.

\subsection{Scope of research}

- This research will modify and develop user interface that facilitate the user to enter the following text content in the course without knowledge of html format, which is the default in open edX:

o Course description

o Course Handout

o Course Update (News)

- This research will develop a new functional module in open edX to input the video component by providing a list of uploaded videos that user can choose from;

- This research will integrate live event from YouTube live streaming to SIT Academy system to allow remote participation or even distance learning concurrently;

- This research will implement a live event page for containing recorded live events of SIT Academy;

- This research will enable and set up CVS file download function by Amazon Simple Storage Service (S3) service to leverage the cloud;

- This research will implement a button to link between SIT Academy website and SIT Academy studio;

- This research will enable and set up Open Response Assessments (ORA) including:

o Self-Assessment

o Peer-Assessment

- This research will enable navigation bar to link with relevant pages including:

o Follow Us links to FB, Twitter, and Google+

o About Us links to About us, Contact us, and FAQ

o Policy links to Terms of Service, Honor Code, and Privacy Policy

- This research will enable and set up certificate of completion of SIT Academy course.

\subsection{Benefits}

- Enhance the learning experience of Thai students via online classroom;

- Provide convenient and beneficial tool for instructors to manage MOOC course efficiently;

- Provide more efficient communication between instructors and students;
- Promote School of Information Technology, King Mongkut's University of Technology Thonburi (KMUTT) as quality educational institution with modern technology.

\section{SYSTEM ANALYSIS}

As present, Massive Open Online Course or MOOC has become a popular learning platform to support worldwide education online. There are several MOOC providers that serve as online classroom and for IT training. edX is a large MOOC platform founded in 2012 by partnership between MIT and Harvard [3]. Currently, edX is the only MOOC provider that allows developers, or any organization including for-profit companies, to implement a MOOC platform locally. That is, the release of open edX [4] allows any organization to host their courses on a MOOC platform independently and receive technical support, rather than requiring the courses to be contributed at edx.org. There are two parts to the system. First is the learning management system which is essentially the interactive online classroom that provides video, course handouts and material, and assignments. The student can learn the course by watching the video lesson along with completing all course assignments. After all assignments and exam were completed, the system can automatically generate a certificate for course completion. Within each course, there is a discussion board that provides community support between the students and instructor. Also, there is student dashboard that supports the tool to help students manage their profile information and their enrolled course. The second part is edX studio as a content management system to allow the instructor to create the course, schedule teaching, and specify grading criteria for the course.

Another well-known MOOC platform is Microsoft Virtual Academy (MVA) [5]. MVA provides free, online training to help IT developers, students and anyone who is interested to learn the latest technology by providing many course categories by topic, product, and popularity. The registered users of MVA can add the course to their learning plan, watch the video, do online assignment and download free book and slide presentation of the course. Besides, the user enroll the course by add the course to learning plan, Microsoft Virtual Academy MOOC was designed to serve the flexible schedule by allow the user add more learning plan that user can add, move, or delete their enrolled course in their learning plan. In each course of MVA indicate several course levels based on the experience of audience, as follows: 100, beginning level for inexperienced person; 200, intermediate level for developers with 6-12 months experience; 300 , advanced level for developers with more than 1 year experience; and 400, Expert level for IT professionals or experts with several years of experience. A student who enrolls in an MVC course is required to finish all given assignment in 
the course in order to complete the course and get a certificate. Some assignments uses the self-assessment methodology by allowing the users review and assess on their response. In the same way, open edX also provides the open response assessments system in course, which includes self-assessment and peer-assessment [6]. In the peer assessment, the users are assigned to assess, or grade the responses of assignments submitted from peers in the same course, and user's responses are assessed by peers in return. To assess the response, a rubric, which is a list of expectations and assess criteria written by instructor, is used as an example response that covers characteristics that each response should have, such as the topics that should be covered. Open response assessment helps the users to be connected and interact with one another in the course, which is consistent with the concept of open education.

Peer-assessment is a way to evaluate the learning results by not applying a formal evaluation process and opening up opportunities for sharing ideas, collaborating via peer to peer with "on-demand accreditation", led by accredited response from education providers [7]. There are some problems and concerns about peer assessment though. First is the limitation of available resources to handle the response engagement and assessment in the process. Another problem is the issue of plagiarism. However, for the MOOC courses that do not offer academic credit, the plagiarism and cheating issues may not be a serious problem for the MOOC course provider.

A special characteristic of learning in MVA course is that users may earn points through the course activities such as watching a video, downloading course handouts, doing self-assessment, or attending a live event. These points will be used to determine the rankings of particular user in the MVA community (global) and country (local) in the Leaderboard. This strategy stimulates and motivates the learning progress and continual learning. Moreover, it creates a competitive environment among learners. Although it makes learners pay attention on their lesson with enthusiasm to participate in the course, it promotes a competitive classroom instead of simply a cooperative classroom. A recent research done in a developing country indicated that the students taught in a cooperative learning environment performed better than students taught in a competitive learning one [8]. The study shows that cooperative and interactive learnings are the most effective to achieve improved performance and produce interaction among learners. In order to connect the students, Microsoft Virtual Academy creates the MVA Community which consists of support communities that allow the students to ask questions, share knowledge, and meet up with one another. This part is designed to be the exchange spaces for and by students for collaborative learning including teamwork activities, using a concept similar to the MOOC design principle based on a pedagogical approach from a learner's perspective [9]. The MVA support community is a single discussion board that opens for student from any MVA course without dividing to particular course and takes advantage of the open community to discuss and share the information widely. Open edX, in the other hand, provide the discussion board only in the particular course. It focuses on discuss topics of the course lesson and share information within the group of students under the same course. For this reason, the discussion board will always be active and the posts related to the lessons are ease to access by students in the course.

Moreover, Microsoft Virtual Academy introduced live events to their MOOC platform. In a live streaming session, it can host any available topic of the latest technology, special class for training, or any IT update on demand of host or course provided. Live streaming provides all audience the opportunity to access a live event in real time, ask the question to expert during the event, and discussion among the participators. This generates incentive and engagement in terms of social conversation. In addition, live events may persuade large number of people who are interested in a particular IT topic but do not have any specific interest to take the course after attending the live event. Furthermore, live events may help to create a positive perspective and value on the organization (as a MOOC provider) in the sense of delivery of new and trendy or up-to-date technology. From one pre-course survey, 95\% of user have high potential to enroll with the reason of "fun and enjoyment", and on the post-course survey, $87 \%$ indicated they have a general interest in the topic. Moreover, $15 \%$ of users used the online course to support their decision on study in college/university classes [7].

Another factor to design and delivery MOOC platform that can engage the students is to step forward to the digital era. As the use of social networks is continually on the rise, many MOOC providers would leverage social media to propagate and release news and information, and use it as a communication channel with the students. EdX, Microsoft Virtual Academy, Coursera, and Udacity all provide many social network channels on Facebook, Twitter, Google+, LinkedIn, YouTube, Reddit, Blog, and so on, in order to engage social interactions and learning cooperation from the students. By leveraging the features of each social networks, Facebook, Twitter, and Google+ are used to update the news and information, YouTube are used as a public video channel, and Blogs are used to enter the contents. Moreover, Social networks have a significant meaning to promote a "feed forward" attitude of sharing. The student can use social network to share their work and knowledge between learners and help learners to create their own personal learning environment on their network [9]. 


\section{METHODOLOGY}

This research aims to develop the SIT Academy, which is a Massive Open Online Course of School of Information Technology, King Mongkut's University of Technology Thonburi as a workable system that provides suitable courses in computer science to Thai high school students as the initial trials. To be a full service system, three major developing tasks are needed. First, SIT Academy is required to enable the additional functions to handle a large number of students doing peer-assessment and self-assessment. Second, it needs to improve and modify some functions that facilitate the instructor or administrator who may receive feedback on the course to enter course content easier and faster without having to enter in the form of HTML. Third, to design and implement new features that provide a better learning environment and community for students of SIT Academy. These new features may focus on creating the social channel in Facebook, Twitter, and Google+, and developing live event streaming to SIT Academy system. An overview of the components of this research work as well as some details of each work are described below.

1. Planning and designing new SIT Academy work flow - this phase plans the overall design of the SIT Academy that consists of evaluating existing edX functions and adding new functions, as well as designing the work flow of SIT Academy, both on the instructor side and the student side.

2. Designing and implement new functions - this phase focuses on design and implementation of new functions to work according to work flow plan.

3. Configuration and setup the SIT Academy - this phase is to set up, as well as enable some functions that are suitable for real course teaching, and ensure the infrastructure would be able to handle the large number of users in the production system.

4. Functional testing and integration testing - this phase is required for testing the system with the new functions. There are two types of tests in this phase. First, functional testing will test the particular function that give the correct output, whether or not it works correctly, and with acceptable failures. Second, integration testing to test the system integration when combining the new functions with existing system.

5. Pilot Course and beta testing - this phase is to create the pilot course of SIT Academy that allows beta users for testing and review the completeness and correctness of all functions and process in a beta course.

6. Evaluating course performance of SIT Academy system - this phase is compare to the existing system in terms of performance metrics by using acceptance testing.

7. Deliver SIT Academy System and deliverable - the last phase is to deliver the production system and documentation including administrator manuals.

\section{DISCUSSION AND SUMMARY}

In this work, we aim to provide high quality education by the use of a Massive Open Online Course project implemented as an SIT Academy web application. It is designed to address the e-learning limitations to enable students to learn more effectively. This is done by incorporating the interactive nature of MOOC into the existing e-learning system. SIT Academy is developed based on open edX in both English and localized Thai. The prototype system is ready for testing in the summer of 2017. With the powerful functions of edX and additional module implementation, the SIT Academy web application emulates an interactive online classroom that provides learning content online. The modules includes video content, course materials and problem solving tasks. With these added features, the SIT Academy should enhance the learning experience of students and help the students to keep focus on the lessons more easily. In addition, the web application has a discussion board that aims to reduce the communication gap between the instructor and student. A beta trial of the integrated SIT Academy is scheduled in the Fall Semester of 2017, to be followed by an extensive analysis of the collected MOOC and other data. Finally, SIT Academy provides several tools that support the instructor to manage the course content and video easily, and also help the instructor measure the effectiveness of teaching by presenting the learning progress of each student in form of statistics and graphs.

\section{References}

[1] Softever, Oliv, 2017. Available as of May 10, 2017 from https://www.facebook.com/Softever-306582356025014/

[2] C. Nukoolkit, P. Chansripiboon, S. Sopitsirikul, "Improving University e-Learning with Exploratory Data Analysis and Web Log Mining", in Proc. The $6^{\text {th }}$ International Conference on Computer Science \& Education, ICCSE 2011, (Singapore; August 3-5, 2011), 2011 .

[3] L. Breslow, D. E. Pritchard, J. DeBoer, G. S. Stump, A. D. Ho, and D. T. Seaton, "Studying learning in the worldwide classroom: Research into edX's first MOOC," Research \& Practice in Assessment, vol. 8, pp. 13-25, 2013. Available as of May 10, 2017 from http://www.rpajournal.com/dev/wpcontent/uploads/2013/05/SF2.pdf.

[4] The Open edX Platform, 2017. Available as of May 10, 2017 from https://github.com/edx/

[5] Microsoft Virtual Academy, 2017. Available as of May 10, 2017 from https://mva.microsoft.com/ 
[6] Open Response Assessments, 2016. Available as of May 10, 2017 from http://edx.readthedocs.org/projects/edxguide-for-students/en/latest/SFD_ORA.html

[7] L. Yuan and S. Powell, "MOOCs and Open Education: Implications for Higher Education," 2013. Available as of May 10, 2017 from http://publications.cetis.org.uk/wpcontent/uploads/2013/03/MOOCs-and-Open-Education.pdf

[8] E. Oloyede, O. Adebowale, and A. Ojo, 2012, "The Effects of Competitive, Cooperative, and Individualistic Classroom
Interaction Models on Learning Outcomes in Mathematics in Nigerian Senior Secondary Schools," hindawi.com, 2012. Available as of January 18, 2016 from

http://www.hindawi.com/journals/isrn/2012/263891/

[9] Lourdes Guàrdia, Marcelo Maina, and Albert Sangrà. "MOOC design principles: A pedagogical approach from the learner's perspective." eLearning Papers, vol. 33, 2013. 